\title{
Comparison of elastic vs. inelastic penstock model using OpenModelica
}

\author{
Vytvytskyi Liubomyr Lie Bernt \\ Department of Electrical engineering, Information Technology and Cybernetics, University College of Southeast Norway, \\ Porsgrunn, Norway, \{Liubomyr.Vytvytskyi, Bernt . Lie\}@usn.no
}

\begin{abstract}
The possibility for modelling and simulating hydropower systems as accurately as possible take an important role in order to develop a control structure and to make efficient analysis tools for testing a designed controller for stability and performance in different operating regimes. Both the simulation time for such models as well as the accuracy are important.
\end{abstract}

A high head hydropower system is considered for this study. The pipe with the main part of the height drop is known as pressure shaft or penstock, and it can be modeled with two levels of accuracy which have been compared in this studying. A simple model with one nonlinear ODE considers inelastic walls of the penstock and incompressible water. A more realistic model for large pressure variations assumes a penstock with elastic walls and compressible water column in the penstock. This more detailed model of a penstock is described with two nonlinear PDEs which have been solved using the Kurganov-Petrova scheme.

Comparing results from these two models it can be concluded that the simple ODE model shows by and large the same results as the PDE model with just slightly smoothed dynamics. Obviously, the simulation time for the inelastic penstock model is considerably smaller. Both models show reasonable results and can be further used for control synthesis and analysis. In cases where the time consumption is most important, the simple ODE model for the penstock is preferred. On the other hand, for more accurate studies the elastic/compressible model for the penstock or even for other waterway units, such as conduit, is more useful.

The modeling part for both cases was done in OpenModelica using our own hydropower library, where all models for different units of the hydropower system have been developed and collected.

Keywords: high head hydropower, penstock/pressure shaft, Kurganov-Petrova scheme, OpenModelica

${ }^{1}$ http://lvk.no/LVK/Fagomrader/Vannkraftproduksjon/ Nokkeltall---Oversikt-over-konsesjonssystemet-for

${ }^{2}$ https://snl.no/vannkraft

${ }^{3}$ https://no.wikipedia.org/wiki/Liste_over_vannkraftverk i_Norge

\section{Introduction}

\subsection{Background}

A transition towards more renewable energy sources is currently happening in Europe and all over the world, with increasing use of flexible hydropower plants to compensate for the highly changing production from intermittent energy sources such as wind and solar irradiation. Flexible hydropower plants involves pumping water up into reservoirs during surplus of intermittent power, and high head storage is the most efficient way to store such surplus power.

Around $96 \%$ of generated electricity (138 GWh) in Norway is produced by hydropower systems, which have a total capacity over $30 \mathrm{GW}$; over 1500 hydropower plants are operated ${ }^{1}$. With these values, Norway occupies the 7th place among the hydropower producers in the world ${ }^{2}$. Among the power plants, the high head hydropower plants generate more than $75 \%$ of all electricity produced from hydropower in Norway ${ }^{3}$.

In addition to hydropower plants, the number of wind power plants in Norway increase from year to year (13.4\% increase in 2015 with respect to $2014^{4}$ ) due to this technology becoming cheaper and more mature. With long coast line, wind power has a huge potential for producing power in Norway ${ }^{5}$. On the other hand, this renewable energy source is intermittent and create considerable disturbances in the power grid. From this perspective, hydropower can be used to compensate for disturbances from the wind power.

To optimize the combination of intermittent power and stored power, the possibilities for modelling and simulating the hydropower system as accurately as possible take an important role in order to make an efficient analysis tool for testing a designed controller for stability and performance in different operating regimes (Sharefi, 2011). 


\subsection{Previous work}

High head plants typically collect and store water in reservoirs in the mountains, with tunnels leading the relatively small flow of water down a considerable height difference to the aggregated turbine and generator. A dynamic model for such a hydropower system has been developed and studied in a previous work (Sharefi, 2011), where the Staggered grid scheme was used for discretization of a part of the model with partial differential equations (PDEs). Another scheme for discretization is the Kurganov-Petrova (KP) scheme, described in (Sharma, 2015; Kurganov \& Petrova, 2007). The comparison of this KP scheme with Staggered grid for an open channel model using Matlab was done in (Vytvytskyi, et al., 2015). In (Saldamli, 2006) a Modelica extension for modeling with partial differential equations, PDEModelica, was proposed. An updated version of PDEModelica with implementation for OpenModelica was recently presented in (Silar, et al., 2017); this extension is not fully completed, though. In addition, a commercial Modelica library for hydropower system exists (Hydro Power Library from Modelon $\mathrm{AB}^{6}$ ), and has been used for modeling a high head hydropower plant in (Winkler, et al., 2011).

\subsection{Overview of paper}

In this work, a simple model of a hydropower system described with ordinary differential equations (ODEs) is compared with a more realistic model described with PDEs in order to find what accuracy level is needed in control synthesis. The current work uses the semidiscrete KP scheme implemented in Modelica for solving the hyperbolic PDEs, which is a novelty compared to the commercial Hydro Power Library.

The paper is structured as follows: Section 2 gives a system description of the high head hydropower system. Section 3 consists of formulation and discretization of the model. Then simulation with validation and comparison of the different model complexities are described in Section 4. Finally, discussion and conclusions are given in Section 5.

\section{System description}

A typical structure for the high head hydropower plant is depicted in Figure $1^{7}$. Here, the water is transported from a reservoir, where it is stored, through a tunnel known as intake race / conduit / headrace closer to the powerhouse where the turbine and generator is installed. The conduit can have considerable length, normally with a small slope.

After the conduit, the water flows down with a steep slope and a relatively small flow rate to the turbine through a pipe known as the penstock or pressure shaft. There is large pressure change in this pipe due to the big height difference. At the point where the penstock is connected to the intake race, a surge tank may be installed to reduce the water hammer pressure variation and keep the mass oscillation within limits. This surge tank can be constructed as a pipe and is then denoted a surge shaft, but can also be variations such as an open or closed reservoir.

After the turbine, the water can flow directly to a downstream lake or river, often denoted tail water, or the

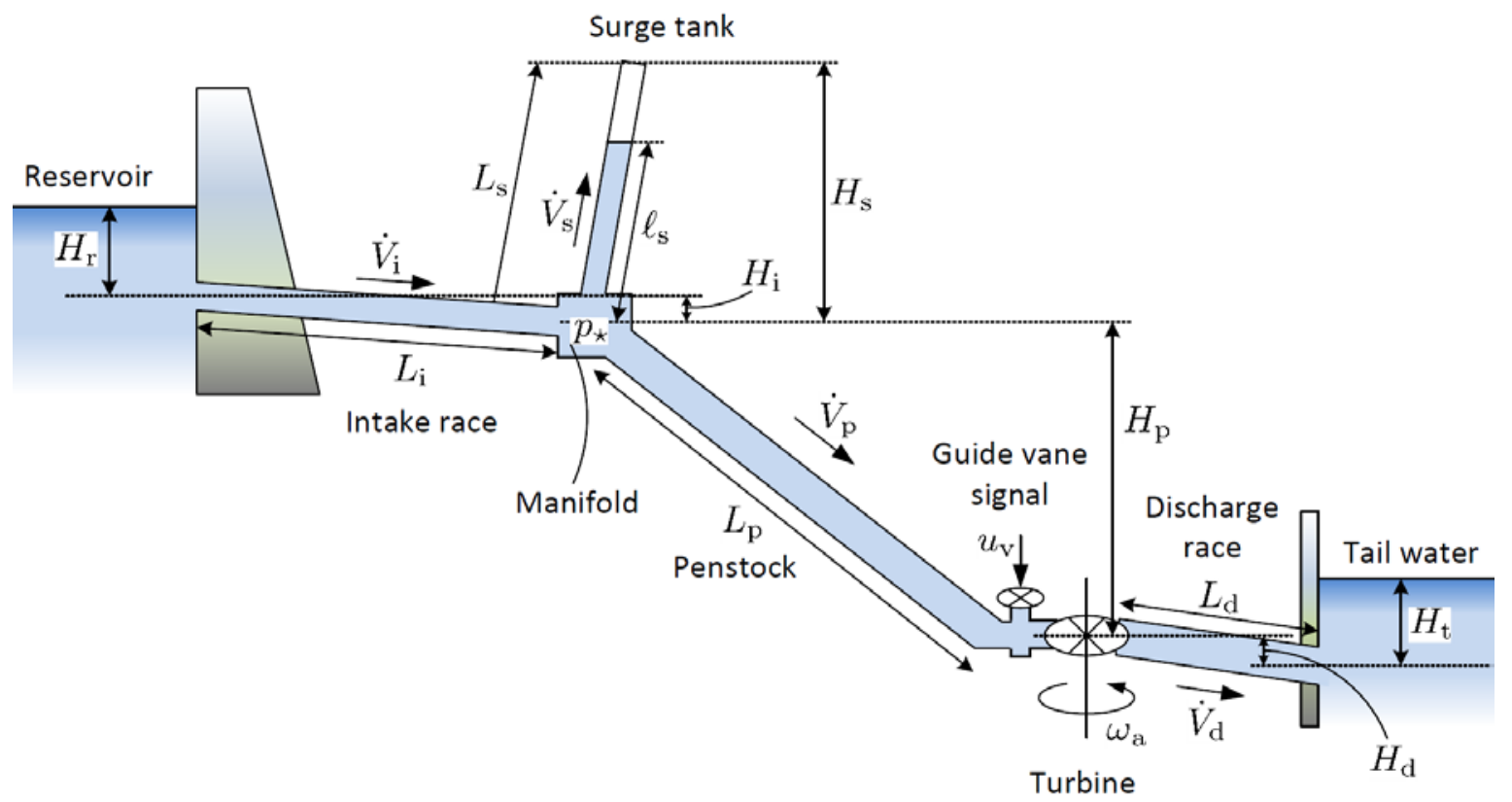

Figure 1. Structure of the high head hydropower plant.

${ }^{6}$ http://www.modelon.com/products/modelicalibraries/hydro-power-library
${ }^{7}$ Agu, C., E., Vytvytskyi, L., Lie, B. (2016) Project, FM1015 Modelling of Dynamic Systems. University College of Southeast Norway, Porsgrunn, Norway. 
water can flow through a discharge race if the powerhouse is situated some distance from the tail water. Normally the turbine is installed below the level of the tail water in order to increase the pressure at the outlet of the turbine to reduce the possibility of cavitation.

Two types of turbines are common for high head hydropower systems. When the height difference is large $(300-4000 \mathrm{~m})$, a Pelton turbine is used with relatively small flow rate $\left(<30 \mathrm{~m}^{3} / \mathrm{s}\right)$. Alternatively, with smaller height differences and large flow rates, Francis turbines are preferred. In our simulations, a Francis turbine is used, and the control of the flow rate through the turbine is done by manipulating the guide vane.

The turbine is rotating an axis which also holds the rotor of the generator producing electricity to the power grid. Normally, a synchronous generator is used.

\subsection{Geometry}

For simulations in this paper, the data from the Sundsbarm hydropower plant in Telemark, Norway is used with data provided in (Winkler, et al., 2011), see Table 1 and Table 2.

Table 1. The waterway geometry of Sundsbarm hydropower plant.

\begin{tabular}{|l|l|l|l|}
\hline $\begin{array}{l}\text { Waterway } \\
\text { unit }\end{array}$ & $\begin{array}{l}\text { Height } \\
\text { difference, } m\end{array}$ & Length, $m$ & Diameter, $m$ \\
\hline Reservoir & 48 & - & - \\
\hline Conduit & 23 & 6600 & 5.8 \\
\hline Penstock & 428.5 & 600 & 3 \\
\hline Surge tank & 120 & 140 & 3.4 \\
\hline $\begin{array}{l}\text { Discharge } \\
\text { race }\end{array}$ & 0.5 & 600 & 5.8 \\
\hline Tail water & 5 & - & - \\
\hline
\end{tabular}

Table 2. The turbine geometry of Sundsbarm hydropower plant.

\begin{tabular}{|l|l|l|l|}
\hline $\begin{array}{l}\text { Turbine } \\
\text { type }\end{array}$ & $\begin{array}{l}\text { Nominal } \\
\text { head, } m\end{array}$ & $\begin{array}{l}\text { Nominal flow } \\
\text { rate, } \mathrm{m}^{3} / \mathrm{s}\end{array}$ & $\begin{array}{l}\text { Nominal } \\
\text { power, } \text { MW }\end{array}$ \\
\hline Francis & 460 & 24.3 & 104.4 \\
\hline
\end{tabular}

\section{Modeling and discretization}

\subsection{Model presentation}

Models for all of the waterway units can be described with mass and momentum balances. For the mechanical part (turbine with aggregate), a simplified energy balance is used assuming that the turbine behaves as a simple valve. All of these models for different units of

\footnotetext{
${ }^{8}$ Modelica ${ }^{\circledR}$ is a non-proprietary, object-oriented, equation based language to conveniently model complex physical systems. https://www.modelica.org

${ }^{9}$ OpenModelica is an open-source Modelica-based modeling and simulation environment intended for
}

the hydropower system have been developed and collected for our own hydropower Modelica ${ }^{8}$ library that can be used in either OpenModelica ${ }^{9}$ or Dymola ${ }^{10}$.

In this paper, a more detailed description is presented for the models that will be compared, namely a simplified pipe (tunnel) model that can be used for the penstock and a more realistic model with compressible water and elastic walls of the penstock.

\subsubsection{Waterway pipe (tunnel)}

In some of the waterway units such as conduit, there are only small pressure variations due to the small slope angle (height difference between inlet and outlet of the component). That is why the model for these units can be simplified by considering incompressibility of the water and inelasticity of the walls. A sketch of the pipe with all needed terms for modeling is shown in Figure 2 .

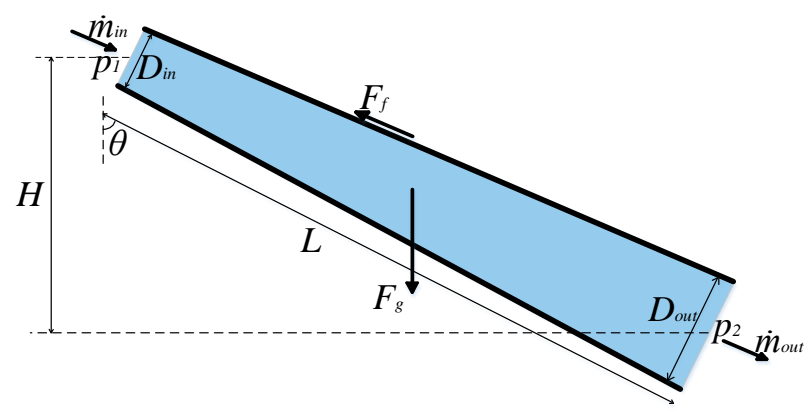

Figure 2. Model for flow through a pipe.

In the case of incompressible water, mass in the filled pipe is constant, and:

$$
\frac{d m}{d t}=\dot{m}_{\text {in }}-\dot{m}_{\text {out }}=0
$$

Here, the mass of the water in the pipe is $m=\rho V=$ $\rho L \bar{A}$, where $\rho$ is the water density, $V$ - the volume of the water in the pipe, $L-$ the length of the pipe and $\bar{A}-$ the averaged cross section area of the pipe that defined from averaged pipe diameter $\bar{D}$. The inlet and outlet mass flow rates are equal with $\dot{m}_{\text {in }}=\rho \dot{V}_{\text {in }}$ and $\dot{m}_{\text {out }}=\rho \dot{V}_{\text {out }}$ respectively, where $\dot{V}_{\text {in }}=\dot{V}_{\text {out }}$ - the inlet and outlet volumetric flow rates in the pipe.

The momentum balance for this simplified model can be expressed as:

$$
\frac{d M}{d t}=\dot{M}_{\text {in }}-\dot{M}_{\text {out }}+F_{p}+F_{g}+F_{f}
$$

Here, the momentum of the water in the pipe is $M=$ $m v$, where $v$ is the average water velocity and can be define as $v=\dot{V} / \bar{A}$. The inlet and outlet momentum flow

industrial and academic usage.

https://www.openmodelica.org

${ }^{10}$ Dymola is a commercial complete tool for modeling and simulating integrated and complex systems; is based on the Modelica open standard language.

http://www.modelon.com/products/dymola 
rates $\quad$ are $\quad \dot{M}_{\text {in }}=\dot{m}_{\text {in }} v_{\text {in }}$ and $\quad \dot{M}_{\text {out }}=\dot{m}_{\text {out }} v_{\text {out }}$ respectively, where $v_{\text {in }}=\dot{V}_{\text {in }} / A_{\text {in }}$ and $v_{\text {out }}=$ $\dot{V}_{\text {out }} / A_{\text {out }}$ are the velocities in the inlet and outlet of the pipe respectively and are equal in a case with constant diameter of the pipe $\left(A_{\text {in }}=A_{\text {out }}\right) . F_{p}$ - the pressure force, due to the difference between the inlet and outlet pressures $p_{1}$ and $p_{2}$ and can be calculated as follows: $F_{p}=A_{\text {in }} p_{1}-A_{\text {out }} p_{2}$. There is also gravity force that is defined as $F_{g}=m g \cos \theta$, where $g$ - the gravitational acceleration and $\theta$ - angle of the pipe slope that can be defined from ratio of height difference and length of the pipe. The last term in the momentum balance is friction force, which can be calculated as $F_{f}=-\frac{1}{8} L f_{D} \pi \rho \bar{D} v|v|$ using Darcy friction factor $f_{D}$.

\subsubsection{Penstock with elastic walls and compressible water}

Unlike the conduit, the penstock has considerable pressure variation due to a considerable height drop. Thus, to make model for the penstock more realistic, compressible water and elastic walls of the penstock should be taken into account. To express the compressibility/elasticity, some compressibility coefficients which show the relationship between pressure, water density and pipe inner radius, are used.

According to (Sharefi, 2011), isothermal compressibility $\beta_{T}$ is defined as follows:

$$
\beta_{T}=\frac{1}{\rho} \frac{d \rho}{d p}
$$

Here $\rho$ and $p$ denote density and pressure, respectively. Assuming that the isothermal compressibility is independent of the pressure, this equation can be rewritten in a way that is convenient to calculate fluid density at different pressures:

$$
\rho=\rho^{\mathrm{atm}} e^{\beta_{T}\left(p-p^{\mathrm{atm}}\right)}
$$

Here $p^{\text {atm }}$ is the atmospheric pressure and $\rho^{\text {atm }}$ is the water density at atmospheric pressure. The relation between density and pressure from this equation can be seen in Figure 3.

Figure 3 shows fairly linear dependency of the density with respect to the pressure in the range that is normal in hydropower plants. That is why the previous equation (4) can be simplified as follows:

$$
\rho \approx \rho^{\mathrm{atm}}\left(1+\beta_{T}\left(p-p^{\mathrm{atm}}\right)\right)
$$

In the same way, the relation between pressure and pipe cross section area can be defined using equivalent compressibility coefficient $\beta^{e q}$ due to the pipe shell elasticity (Sharefi, 2011); after simplification the relation looks as follows:

$$
A \approx A^{\mathrm{atm}}\left(1+\beta^{e q}\left(p-p^{\mathrm{atm}}\right)\right)
$$

Here $A^{\text {atm }}$ is the pipe cross section area at atmospheric pressure.

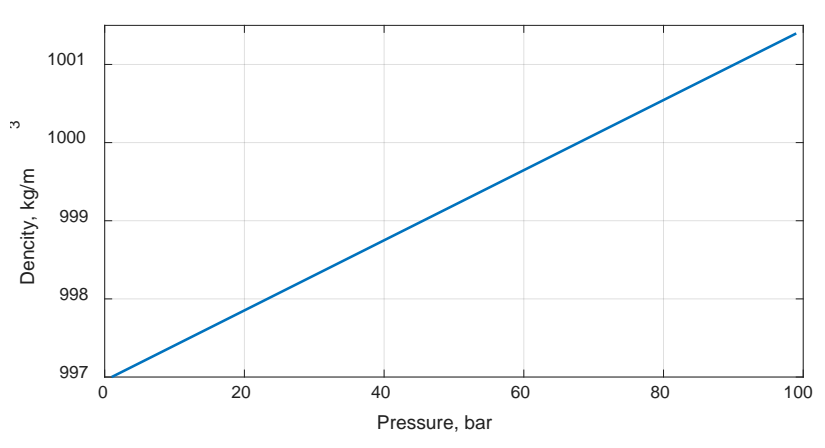

Figure 3. Variation of density with respect to pressure.

In reference to (Sharefi, 2011), it is also possible to define a linear relationship for the product of density and cross sectional area that change with pressure.

$$
A \cdot \rho=A^{\mathrm{atm}} \rho^{\mathrm{atm}}\left(1+\beta^{\text {tot }}\left(p-p^{\mathrm{atm}}\right)\right)
$$

Here $\beta^{\text {tot }}$ is the total compressibility due to water compressibility and pipe shell elasticity $\left(\beta^{t o t}=\beta^{e q}+\right.$ $\beta_{T}$ ), and is related to the speed of sound in water inside the pipe.

Hence, using the previous equations for the relationship between density of the water, cross sectional area of the pipe, and pressure in the pipe, ODEs (1) and (2) for mass and momentum balances can be further developed into the PDEs:

$$
\begin{gathered}
A^{\mathrm{atm}} \rho^{\mathrm{atm}} \beta^{t o t} \frac{\partial p}{\partial t}=-\frac{\partial \dot{m}}{\partial x} \\
\frac{\partial \dot{m}}{\partial t}=-\frac{\partial}{\partial x}(\dot{m} v+A p)+\rho A g \cos \theta \\
-\frac{1}{8} f_{D} \pi \rho D v|v|
\end{gathered}
$$

\subsection{Model discretization}

There are many discretization techniques for PDEs, but from previous work (Vytvytskyi, et al., 2015) it was observed that the well-balanced second order Kurganov-Petrova (KP) scheme shows reasonably good results for hyperbolic PDEs. The KP scheme is therefore also chosen for discretization of the model for the elastic penstock with compressible water. The detailed development of the KP scheme is shown in (Kurganov \& Petrova, 2007) with some run-of-river case studies in (Sharma, 2015; Vytvytskyi, et al., 2015; Dissanayake, et al., 2016; Dissanayake, et al., 2017).

Firstly, PDEs (8) for the elastic penstock model should be presented in vector form as a standard formulation for KP scheme (Sharma, 2015):

$$
\frac{\partial U}{\partial t}+\frac{\partial F}{\partial x}=S
$$

with: $\quad U=\left[\begin{array}{ll}p, & \dot{m}\end{array}\right]^{T}-$ vector of conserved variables,

fluxes,

$$
F=\left[\frac{\dot{m}}{A^{\text {atm }} \rho^{\text {atm }} \beta^{\text {tot }}}, \quad \dot{m} v+A p\right]^{T}-\quad \text { vector of }
$$

$$
S=\left[0, \quad \rho A g \cos \theta-\frac{1}{8} f_{D} \pi \rho D v|v|\right]^{T}-\text { source }
$$

terms vector. 
The result of discretizing the elastic penstock model using the KP scheme is the semi-discrete (time dependent ODEs) central-upwind scheme and can be written in the following from:

$$
\frac{d}{d t} \bar{U}_{i}(t)=-\frac{H_{i+\frac{1}{2}}(t)-H_{i-\frac{1}{2}}(t)}{\Delta x}+\bar{S}_{i}(t)
$$

Here, $\bar{U}_{i}$ is the cell center averaged values while $H_{i \pm \frac{1}{2}}-$ the central upwind numerical fluxes at the cell interfaces, are defined as:

$$
\begin{array}{r}
H_{i+\frac{1}{2}}(t)=\frac{a_{i+\frac{1}{2}}^{+} F\left(U_{i+\frac{1}{2}}^{-}\right)-a_{i+\frac{1}{2}}^{-} F\left(U_{i+\frac{1}{2}}^{+}\right)}{a_{i+\frac{1}{2}}^{+}-a_{i+\frac{1}{2}}^{-}} \\
+\frac{a_{i+\frac{1}{2}}^{+} a_{i+\frac{1}{2}}^{-}}{a_{i+\frac{1}{2}}^{+}-a_{i+\frac{1}{2}}^{-}}\left[U_{i+\frac{1}{2}}^{+}-U_{i+\frac{1}{2}}^{-}\right] \\
H_{i-\frac{1}{2}}(t)=\frac{a_{i-\frac{1}{2}}^{+} F\left(U_{i-\frac{1}{2}}^{-}\right)-a_{i-\frac{1}{2}}^{-} F\left(U_{i-\frac{1}{2}}^{+}\right)}{a_{i-\frac{1}{2}}^{+}-a_{i-\frac{1}{2}}^{-}} \\
+\frac{a_{i-\frac{1}{2}}^{+} a_{i-\frac{1}{2}}^{-}}{a_{i-\frac{1}{2}}^{+}-a_{i-\frac{1}{2}}^{-}}\left[U_{i-\frac{1}{2}}^{+}-U_{i-\frac{1}{2}}^{-}\right]
\end{array}
$$

Here $a_{i \pm \frac{1}{2}}^{ \pm}$are the one-side local speeds of propagation, and can be defined as the smallest and the largest eigenvalues of the Jacobian $\frac{\partial F}{\partial U}$ of the system. These eigenvalues become:

$$
\lambda_{1,2}=\frac{v \pm \sqrt{v^{2}+\frac{4 A}{A^{\mathrm{atm}} \rho^{\mathrm{atm}} \beta^{t o t}}}}{2}
$$

From these eigenvalues, it can be deduced that the speed of sound is given as $c=\sqrt{\frac{A}{A^{\text {atm }} \rho^{\text {atm } \beta^{\text {tot }}}}}$, thus confirming that the total compressibility factor $\beta^{\text {tot }}$ is related to the speed of sound.

\subsection{Operational data and parameters}

The complete set of models for different units of the hydropower system now consists of a number of ODEs that can be simulated in OpenModelica or Dymola with the der operator for $d / d t$ using the dassl solver algorithm with simulation interval time equal to $0.4 \mathrm{~s}$ and tolerance 1e-4. All operational parameters for simulation are given in Table 3 .

\section{Simulation}

Firstly, basic simulations of the system with various penstock models (inelastic and elastic penstock) are done to validate the models from our own library with a commercial one. Then, a more detailed comparison of models with different penstock complexities is given for various simulation scenarios.
Table 3. Parameters for simulating the high head hydropower system.

\begin{tabular}{|c|l|l|l|}
\hline Variable & Value & Unit & Comments \\
\hline$g$ & 9.81 & $\mathrm{~m} / \mathrm{s}^{2}$ & $\begin{array}{l}\text { Acceleration due to } \\
\text { gravity }\end{array}$ \\
\hline$\rho\left(\rho^{\mathrm{atm}}\right)$ & 997 & $\mathrm{~kg} / \mathrm{m}^{3}$ & Density of water \\
\hline$\mu$ & $0.89 \mathrm{e}-3$ & $\mathrm{~Pa} \cdot \mathrm{s}$ & $\begin{array}{l}\text { Dynamic viscosity of } \\
\text { water }\end{array}$ \\
\hline$\epsilon$ & $1.5 \mathrm{e}-5$ & $\mathrm{~m}$ & Pipe roughness height \\
\hline$\beta_{T}$ & $4.5 \mathrm{e}-10$ & $\mathrm{~Pa}^{-1}$ & Water compressibility \\
\hline$\beta^{\text {tot }}$ & $1.003 \mathrm{e}-9$ & $\mathrm{~Pa}^{-1}$ & Total compressibility \\
\hline$p^{\mathrm{atm}}$ & $1.013 \mathrm{e} 5$ & $\mathrm{~Pa}$ & Atmospheric pressure \\
\hline$\Delta x$ & 60 & $\mathrm{~m}$ & $\begin{array}{l}\text { Cell length for } \\
\text { penstock discretization }\end{array}$ \\
\hline$C_{V}$ & 3.7 & $\mathrm{~m} / \mathrm{s}$ & Turbine valve capacity \\
\hline$\eta_{h}$ & 0.9 & - & $\begin{array}{l}\text { Turbine hydraulic } \\
\text { efficiency }\end{array}$ \\
\hline$\eta_{e}$ & 0.99 & - & $\begin{array}{l}\text { Electricity generator } \\
\text { efficiency }\end{array}$ \\
\hline$J_{a}$ & $2 \mathrm{e} 5$ & $\mathrm{~kg} \cdot \mathrm{m}^{2}$ & $\begin{array}{l}\text { Moment of inertia of } \\
\text { the aggregate }\end{array}$ \\
\hline$k_{f, b}$ & $1 \mathrm{e} 3$ & $\frac{\mathrm{W} \cdot \mathrm{s}^{2}}{\mathrm{rad} \mathrm{d}^{2}}$ & $\begin{array}{l}\text { Friction factor in the } \\
\text { aggregate bearing }\end{array}$ \\
\hline
\end{tabular}

\subsection{Validation}

It is of interest to validate the developed models with the commercial Hydro Power Library in order to check that our own library shows reasonable results; some basic simulation is done for this validation. The scenario for this simulation is a simple turbine guide vane (valve) opening after time $30 \mathrm{~s}$ from $10 \%$ over a period of $30 \mathrm{~s}$ to $100 \%$. The block diagrams for the hydropower systems using the Hydro Power Library and our own developed models are shown in Figure 4.

In case of both libraries, the turbine is presented as a simple valve. That is why the turbine valve capacity together with the pipe roughness height should be set to similar or equivalent values. After some tuning of these variables for our in-house models, the results of the simulation fits the results from the Modelon Hydro Power Library reasonably well and are shown in Figure 5: the pressure drop variations through the turbine are presented for different cases.

From Figure 5, it is seen that the system with simple, inelastic penstock shows smother dynamics after the beginning of disturbance (at time after $30 \mathrm{sec}$.), while some small oscillation take part in the results for the inhouse elastic penstock model and using the Modelon Hydro Power Library. It should also be noted that the simulation time for the system with inelastic penstock is around one third of the two other models. 


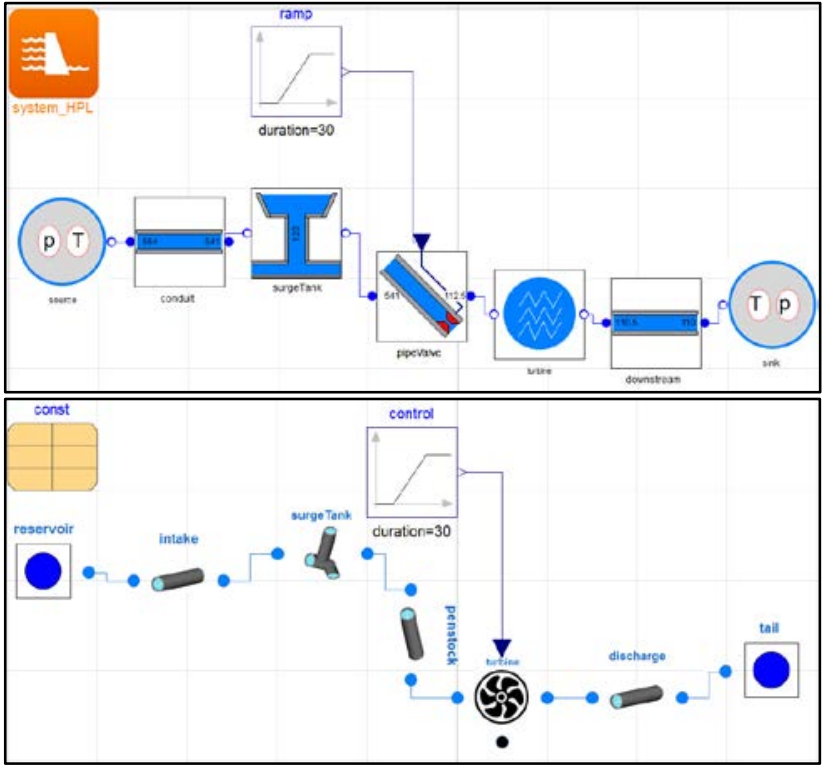

Figure 4. Block diagrams for hydropower system using Hydro Power Library (upper) and in-house library (lower).

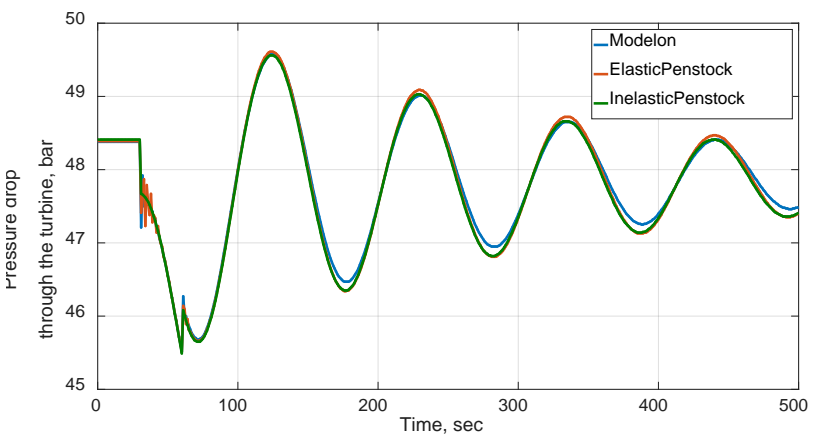

Figure 5. Validation of simulation results from own developed models (elastic and inelastic penstock) with Hydro Power Library.

\subsection{Comparison}

\subsubsection{First simulation scenario}

With the rudimentary validation in the previous section, a more detailed comparison of models with different penstock complexities can be studied. Firstly, the simulation scenario with sudden and small closing of the turbine guide vane (valve) is considered. Here, the systems are being simulated for $2000 \mathrm{~s}$ and the disturbance is applied at $600 \mathrm{~s}$, when the valve is closed by $5 \%$ within $1 \mathrm{~s}$. The results of simulation of the inelastic and the compressible/elastic models are presented in Figure 6, where plots are zoomed and shows just the time interval around disturbance (550 $750 \mathrm{sec}$. $)^{11}$. In this figure the comparison of the pressure drop through the turbine (upper plot) and volumetric flow rate on the turbine (lower plot) are given for both

\footnotetext{
11 The disturbance is not applied earlier in order to reach the steady state for the systems.
}

cases: systems with elastic and inelastic penstock models.

We observe smoother dynamics after disturbance for the inelastic penstock for both pressure drop and volumetric flow rate in Figure 6, which is similar to the validation case. From a power production perspective, this difference looks insignificant and may be neglected for control purposes if we take into account that the simulation time for a system with elastic penstock model is 3 times longer. On the other hand, it may be extremely important to observe these pressure oscillations to avoid cavitation and wear and tear of the turbine. That is why the outlet turbine pressure is also presented (see Figure 7) in order to compare models with elastic and inelastic penstock from the perspective of the cavitation problem.

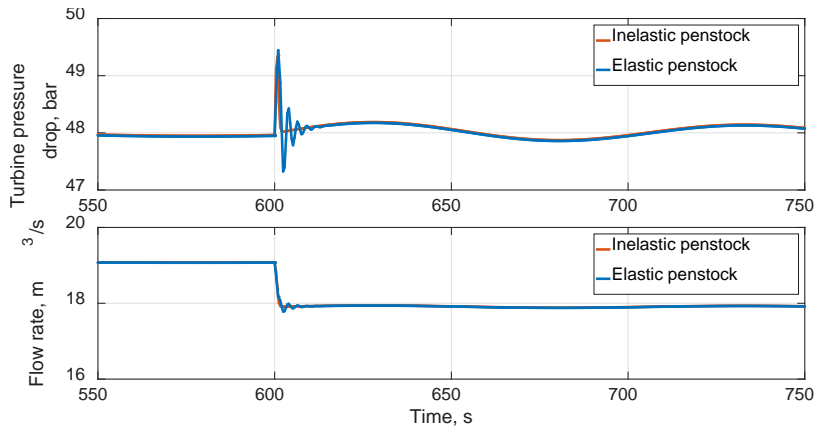

Figure 6. Comparison of simulation results for the systems with elastic vs. inelastic penstock models.

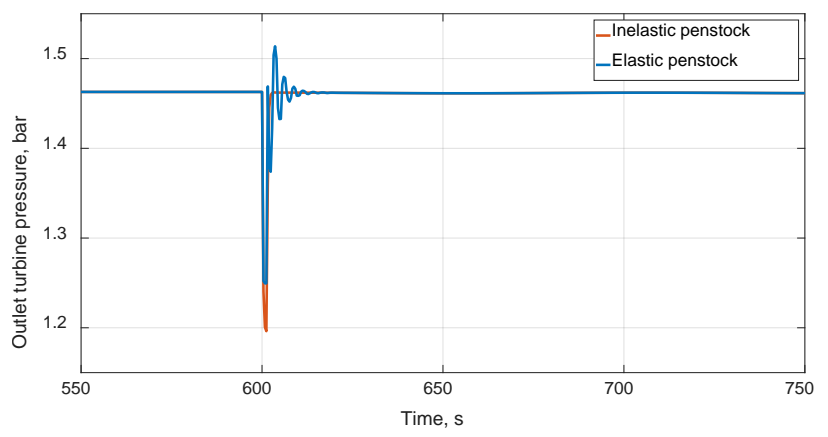

Figure 7. Comparison of the outlet turbine pressure for the systems with elastic vs. inelastic penstock models.

Figure 7 shows the same smoother dynamics with the simple inelastic penstock model, but the amplitude of the first oscillation is slightly higher for the model with elastic penstock.

\subsubsection{Second simulation scenario}

It is of interest to check another simulation scenario to see the effect of the penstock model complexity: a system without surge tank, but with the same disturbance as in the previous case (5\% turbine valve closing at time $600 \mathrm{~s}$ ). The results of simulating this scenario is shown in Figure 8, where only the 
comparison of the pressure drop through the turbine is presented; the volumetric flow rate through the turbine shows similar results as in the previous simulation.

From Figure 8, it is seen that amplitudes of the first oscillation are different: in the system with inelastic penstock model the pressure drop rise higher after the disturbance than in the system with elastic penstock model. This difference can be related to the speed of increasing the pressure drop after disturbance: the pressure drop rises faster in the case with inelastic penstock model.

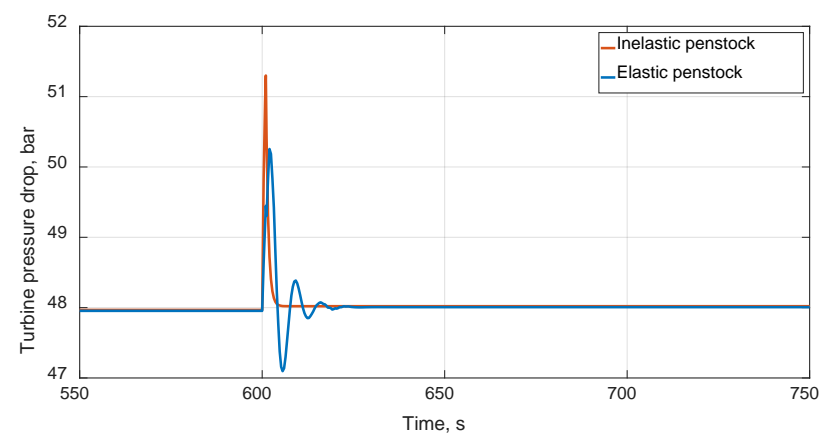

Figure 8. Comparison of the simulation results for the systems without surge tank.

It is also of interest, for these two penstock models, to see the difference at the outlet pressure from the turbine, which takes an important role in cavitation studies: due to the difference between the pressure drops through the turbine, here a point is to check from which side, inlet/outlet, of the turbine this difference was caused. Thus, this outlet turbine pressure is compared in Figure 9, where the simulation scenario is still the same (system without surge tank and 5\% closing of the guide vane at time $600 \mathrm{~s}$ ). Here, it is observed that the dynamics slightly differ between the system with elastic and inelastic penstock models, but the amplitude of the oscillation just after the disturbance is similar. This means that the inlet pressure to the turbine causes the difference in the turbine pressure drop.

The wave propagation is taken into account in the system with elastic penstock model and that is why models take some longer time for the turbine pressure drop to reach the maximum amplitude of the first oscillation after the disturbance, while in the system with inelastic penstock model all variables change simultaneously through the whole system. This can be observed in Figure 10, where the volumetric flow rate through the conduit is compared for cases with elastic vs. inelastic penstock models. Here, the flow rate through the conduit for the system with inelastic penstock starts to decrease at the time (600 s) when the disturbance occurs, while around half a second is needed for the wave in the system with elastic penstock model to reach the conduit.

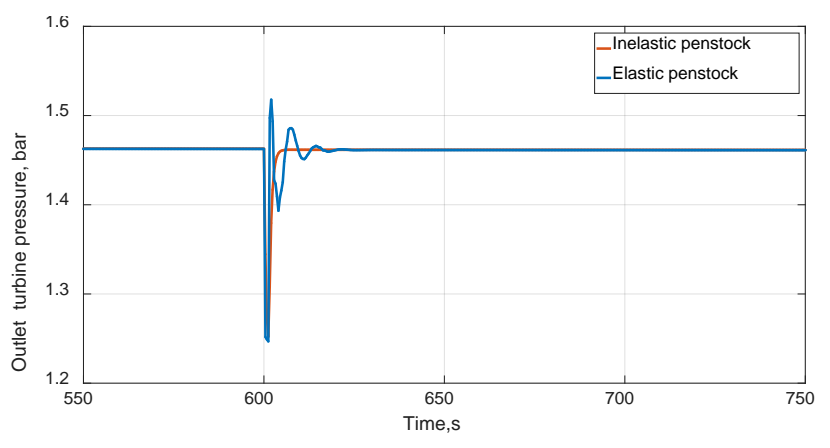

Figure 9. Comparison of the outlet turbine pressure for the systems without surge tank.

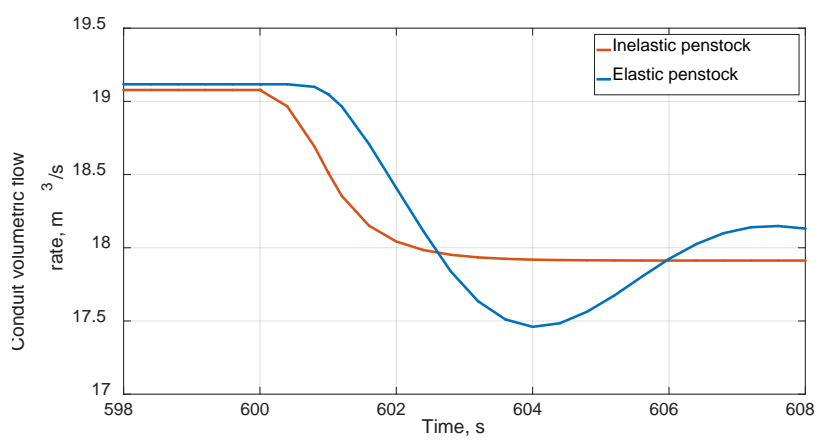

Figure 10. Comparison of the wave propagation in the systems with elastic vs. inelastic penstock models.

\subsubsection{Third simulation scenario}

In the last scenario, the effect of the wave propagation in the longest part of the hydropower system is studied. For this case, the elastic penstock model with compressible water is used for the conduit and the penstock units; the disturbance is the same as it was in the previous two scenarios. The simulations are done for both systems with (see Figure 11) and without (see Figure 12) surge tank and the turbine pressure drop is compared with the results for the previous two scenarios. It should be noted that the elastic model for the conduit is discretize with the same step length as for the penstock $(60 \mathrm{~m})$ and it leads to dramatic increasing of the simulation time, around 20-30 times.

From Figure 11, it is seen that the results for all three cases look almost the same. The system with the elastic conduit shows slightly more oscillatory results, but in general, there are no difference in overall dynamics. On the other hand, the dynamics differ substantially for the system without surge tank; the case with elastic conduit give a rather different behavior, which can be seen in Figure 12. Here, the oscillations after the disturbance need more time to reach a new steady state (compared to two other cases) and the amplitude of the first oscillation for the elastic conduit case is lower than for systems with elastic or inelastic penstock models. 


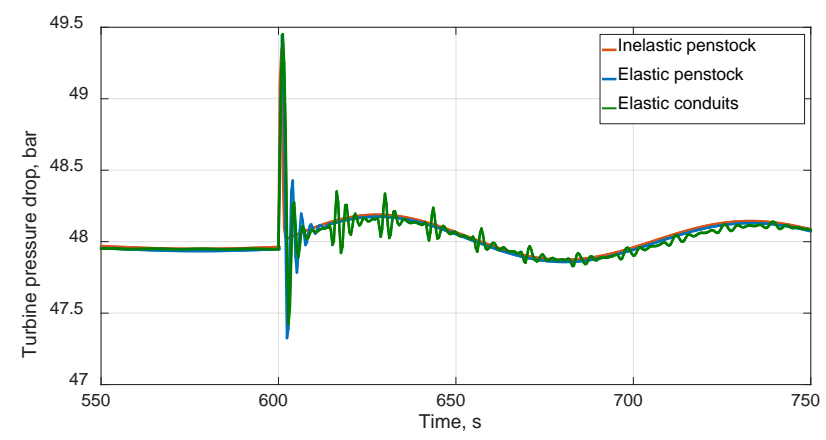

Figure 11. Comparison of the elastic conduit for the system with surge tank.

The longer oscillation time for the system with elastic penstock and conduit models is caused by the water wave moving back and forth (up and down) through the whole system. This is actually one of the reasons of using the surge tank: to keep mass oscillations within the limits: the oscillations in the system with surge tanks are much smother and their amplitude variation is smaller.

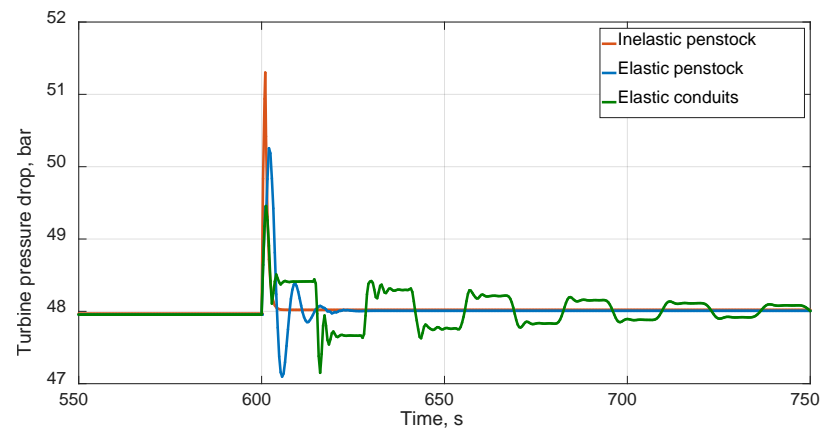

Figure 12. Comparison of the elastic conduit for the system without surge tank.

It is also of interest to compare the behavior of the outlet turbine pressure for the elastic model of the conduit. Thus, the comparisons have been done for both systems with and without the surge tank and results are shown in Figure 13 and Figure 14. Both figures show that the model with both the elastic conduit and penstock behaves more oscillatory, and at the same time, reaches the maximum amplitude values similar to the model with just the elastic penstock.

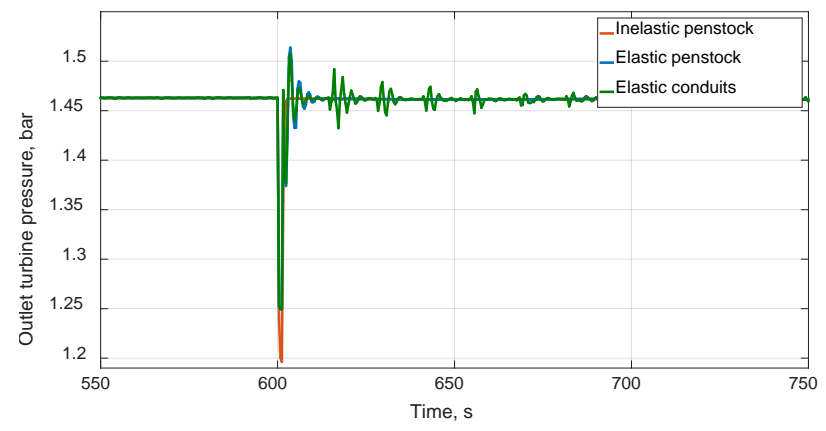

Figure 13. Comparison of the outlet turbine pressure for the systems with surge tank.

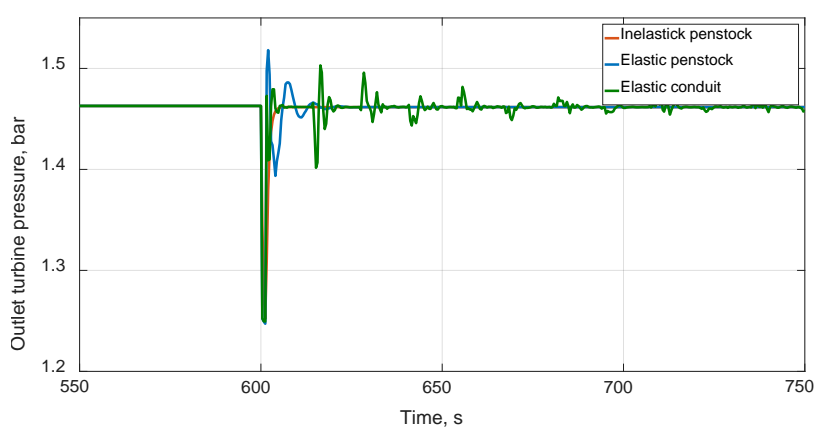

Figure 14. Comparison of the outlet turbine pressure for the systems without surge tank.

\section{Discussion and conclusion}

In this paper, the comparison of different penstock models for modeling and simulation of a high head hydropower system has been explored. The KurganovPetrova second order central upwind scheme has been implemented to discretize the more complicated penstock model with compressible water and elastic walls that is described by PDEs. This scheme has been implemented in Modelica and collected into an in-house library together with all other models for the hydropower elements. Then the models for simulating the hydropower system with different scenarios have been developed and simulated in OpenModelica. This in-house hydropower library has been validated with an already existing commercial Hydro Power Library.

Based on three simulation scenarios, it can be concluded that the system with inelastic penstock model exhibits a somewhat simpler dynamics, but on the other hand it has an advantage in the simulation time which is only one third of the same system but just with elastic penstock model (discretized by KP scheme). It is also observed that the wave propagation, which is taken into account in the elastic penstock model, affects the system, in particular the one without a surge tank. This effect leads to longer oscillations but also a smaller amplitude just after the disturbance (system without the surge tank). Despite all these difference, the inelastic penstock model can perhaps be used for control design problems due to the simplicity of this model, being less time consuming for simulation and reasonably good accuracy. Clearly, a model based controller based on a simple model should be tested on a more rigorous model, and, if necessary, re-tuned in order to ensure good performance. For a more detailed and accurate design, the elastic penstock model could be used in the controller, due to better representation of the system dynamics, which is caused by including the speed of the wave propagation to the model. Even better dynamic representation of the system can be reached by using the elastic model for the conduit. Then the delay caused by the speed of the wave propagation leads to more dramatic changes in the system dynamics (well observed in Figure 12). 
Finally, our limited experience indicates that the simpler model appears to cover the worst case due to higher amplitude of the oscillation just after disturbance, even though it does not show proper dynamics. The systems with elastic and inelastic models do not behave in the same way for the outlet turbine pressure, the amplitude of the first oscillation after disturbance can differ, and this can be extremely important for a cavitation study.

\section{References}

Dissanayake, S., Sharma, R. \& Lie, B., 2016. Semi Discrete Scheme for the Solution of Flow in River Tinnelva.. Oulu, Finland, EUROSIM 2016. IEEE, pp. 134-139.

Dissanayake, S., Sharma, R. \& Lie, B., 2017. Third Order Reconstruction of the KP Scheme for Model of River Tinnelva.. Modeling, Identification and Control, 38(1), p. 33-50.

Kurganov, A. \& Petrova, G., 2007. A second order wellbalanced positivity preserving central-upwind scheme for the saint-venant system. Communications in Mathematical Science, Volume 5(1), p. 133-160..

Saldamli, L., 2006. PDEModelica A High-Level Language for Modeling with Partial Differential Equations, Linköping, Sweden: Department of Computer and Information Science Linköping University.

Sharefi, B. R., 2011. Modeling for Control of Hydropower Systems, Porsgrunn, Norway.: Master's Thesis.Telemark University College .

Sharma, R., 2015. Second order scheme for open channel flow., Porsgrunn, Norway: Technical report, Telemark Open Research Archive (TEORA), Telemark University College.

Silar, J., Jezek, F. \& Kofranek, J., 2017. PDEModelica and Breathing in an Avalanche. Prague, Czech Republic, Proceedings of the 12th International Modelica Conference.

Vytvytskyi, L., Sharma, R. \& Lie, B., 2015. Model based control for run-of-river system. Part 1: Model implementation and tuning. Modeling, Identification and Control, 36(4), p. 237-249.

Winkler, D. et al., 2011. Modelling and Optimisation of Deviation in Hydro Power Production. Dresden, Germany, Modelica Conference. 